\title{
Medicare Bundled Payment Initiative Did Not Reduce COPD Readmissions
}

Implementation of the Medicare bundled payments for care improvement initiative has failed to cut readmission rates following hospitalization for acute exacerbation of chronic obstructive pulmonary disease (COPD), according to a study published in the Annals of the American Thoracic Society (1).

Bhatt and colleagues (1) from the University of Alabama at Birmingham enrolled 78 consecutive Medicare patients in 2014 compared to 109 patients in the historic group from 2012. They found that patients from 2014 were more likely to have compliance with the bundled care payment requirements. However, there was no difference in all-cause readmission rates at 30 days (15.4\% vs.17.4\%; $\mathrm{p}=.711)$, and 90 days $(26.9 \%$ vs $33.9 \% ; \mathrm{p}=.306)$.

The bundled care requirements include regular follow-up phone calls, pneumococcal and influenza vaccines, home health care, durable medical equipment, pulmonary rehabilitation, and to attend pulmonary clinic which were significantly increased after implementation of the bundled care requirements. However, these COPD interventions were implemented despite having not been shown to decrease COPD readmissions (2). Furthermore, Shah et al. (3) have reported that only $27.6 \%$ of COPD hospital readmissions are for COPD making these COPD interventions even less likely to reduce readmissions.

\section{References}

1. Bhatt SP, Wells JM, lyer AS, et al. Results of a Medicare Bundled Payments for Care Improvement Initiative for COPD Readmissions. Ann Am Thorac Soc. 2016 Dec 22 [Epub ahead of print]. [CrossRef] [PubMed]

2. Robbins RA, Wesselius LJ. Reducing readmissions after a COPD exacerbation: a brief review. Southwest J Pulm Crit Care. 2015;11(1):19-24. [CrossRef]

3. Shah T, Churpek MM, Coca Perraillon M, Konetzka RT. Understanding why patients with COPD get readmitted: a large national study to delineate the medicare population for the readmissions penalty expansion. Chest. 2015;147(5):1219-26. [CrossRef] [PubMed] 